\title{
Social Incentives and Gamification to Promote Weight Loss: The LOSE IT Randomized, Controlled Trial
}

\author{
Gregory W. Kurtzman, BA ${ }^{1,2}$, susan C. Day, MD, MPH' , Dylan S. Small, $P \mathrm{DD}^{3}$, \\ Marta Lynch, BS ${ }^{2}$, Jingsan Zhu, MBA, $M S^{l}$, Wenli Wang, $M S^{l}$, Charles A. L. Rareshide, $M S^{2}$, \\ and Mitesh S. Patel, MD, MBA, MS ${ }^{1,2,3,4}$
}

${ }^{1}$ Perelman School of Medicine, University of Pennsylvania, Philadelphia, PA, USA; ${ }^{2}$ Penn Medicine Nudge Unit, Philadelphia, PA, USA; ${ }^{3}$ The Wharton School, University of Pennsylvania, Philadelphia, PA, USA; ${ }^{4}$ Crescenz Veterans Affairs Medical Center, Philadelphia, PA, USA.

BACKGROUND: Social networks influence obesity patterns, but interventions to leverage social incentives to promote weight loss have not been well evaluated.

OBJECTIVE: To test the effectiveness of gamification interventions designed using insights from behavioral economics to enhance social incentives to promote weight loss.

DESIGN: The Leveraging Our Social Experiences and Incentives Trial (LOSE IT) was a 36-week randomized, controlled trial with a 24 -week intervention and 12-week follow-up.

PARTICIPANTS: One hundred and ninety-six obese adults (body mass index $\geq 30$ ) comprising 98 two-person teams.

INTERVENTIONS: All participants received a wireless weight scale, used smartphones to track daily step counts, formed two-person teams with a family member or friend, and selected a weight loss goal. Teams were randomly assigned to control or one of two gamification interventions for 36 weeks that used points and levels to enhance collaborative social incentives. One of the gamification arms also had weight and step data shared regularly with each participant's primary care physician (PCP). MAIN OUTCOME MEASURES: The primary outcome was weight loss at 24 weeks. Secondary outcomes included weight loss at 36 weeks.

KEY RESULTS: At 24 weeks, participants lost significant weight from baseline in the control arm (mean: $-3.9 \mathrm{lbs}$; 95\% CI: -6.1 to $-1.7 ; P<0.001)$, the gamification arm (mean: $-6.6 \mathrm{lbs} ; 95 \% \mathrm{CI}:-9.4$ to $-3.9 ; P<0.001$ ), and the gamification arm with PCP data sharing (mean:$4.8 \mathrm{lbs} ; 95 \%$ CI: -7.4 to -2.3 ; $P<0.001$ ). At 36 weeks, weight loss from baseline remained significant in the control arm (mean: $-3.5 \mathrm{lbs} ; 95 \% \mathrm{CI}:-6.1$ to $-0.8 ; P=0.01$ ), the gamification arm (mean: $-6.3 \mathrm{lbs} ; 95 \% \mathrm{CI}$ : -9.2 to 3.3; $P<0.001)$, and the gamification arm with PCP data sharing (mean: $-5.2 \mathrm{lbs} ; 95 \% \mathrm{CI}:-8.5$ to $-2.0 ; P<0.01$ ). However, in the main adjusted model, there were no significant differences in weight loss between each of the intervention arms and control at either 12, 24, or 36 weeks.

$\overline{\text { Electronic supplementary material The online version of this article }}$ (https://doi.org/10.1007/s11606-018-4552-1) contains supplementary material, which is available to authorized users.

Received January 4, 2018

Revised April 25, 2018

Accepted June 18, 2018

Published online July 12, 2018
CONCLUSIONS: Using digital health devices to track behavior with a partner led to significant weight loss through 36 weeks, but the gamification interventions were not effective at promoting weight loss when compared to control.

TRIAL REGISTRATION: clinicaltrials.gov Identifier: 02564445

KEY WORDS: gamification; behavioral economics; social incentives; weight loss; physical activity; clinical trial; smartphones.

J Gen Intern Med 33(10):1669-75

DOI: $10.1007 / \mathrm{s} 11606-018-4552-1$

() This is a U.S. government work and not under copyright protection in the U.S.; foreign copyright protection may apply 2018

\section{INTRODUCTION}

Nearly $40 \%$ of adults in the USA are obese. ${ }^{1}$ Excess weight gain is associated with worse health outcomes including higher rates of cardiovascular disease, diabetes, and hypertension. $^{2}$ Interest in weight loss program is significant with more than $50 \%$ of adults reporting that they are actively trying to lose weight. ${ }^{3}$

National guidelines for the management of obesity have highlighted the importance of primary care models for promoting weight loss among overweight and obese adults. ${ }^{4,5}$ However, primary care physicians (PCPs) face many challenges incorporating these recommendations into practice. ${ }^{6}$ PCPs often lack tools to monitor patients' weight, diet, and physical activity outside of the office visit. Moreover, effective programs to motivate patients to lose and sustain weight change are lacking.

Gamification is the use of game design elements, such as points and levels, and is increasingly being used in digital health interventions to promote behavior change, such as weight loss and physical activity. ${ }^{7-10}$ In a clinical trial, we previously demonstrated how insights from behavioral economics could be used to design gamification interventions to enhance social incentives and significantly increase physical activity. ${ }^{11}$ These types of interventions leverage remotemonitoring technologies and could be deployed in primary care settings to promote weight loss. 
In this study, our objective was to conduct a randomized, controlled trial to test the effectiveness of a gamification intervention that used insights from behavioral economics to enhance social incentives, such as collaboration, accountability, and peer support to promote weight loss. To test the optimal approach to implement this within a primary care setting, we compared a control group to a gamification intervention with and without sharing data with the PCP. We also incorporated several novel approaches that leverage technology to improve scalability, such as digital health devices to remotely monitor weight and step data, conducting virtual weigh-ins through smartphone-based video conferencing, and automating data sharing to the electronic health record through Apple HealthKit's integration with EPIC.

\section{METHODS}

\section{Study Design}

LOSE IT (Leveraging Our Social Experiences and Incentives Trial) was a 36-week randomized, controlled trial conducted between January 25, 2016 and November 21, 2016 consisting of a 24-week intervention period and a 12-week follow-up period. The study protocol is available (Online Appendix 1) and was approved by the University of Pennsylvania Institutional Review Board.

The study was conducted using Way to Health, a research platform at the University of Pennsylvania used previously for behavioral interventions. ${ }^{11-15}$ Interested participants were asked to form teams of two with a family member or friend. Each participant used the study website to create an account, provide online informed consent, and complete baseline eligibility surveys. Eligible participants were scheduled for an inperson visit with their teammate, during which they downloaded the smartphone application (Withings HealthMate), which our previous study found to be accurate at tracking track daily step counts. ${ }^{16}$ During the visit, each participant was setup with a wireless weight scale (Withings WS-30) to capture a baseline weight and take home for use. Participants were given a goal of 10,000 steps per day and asked to select a weight loss goal in pounds between 6 and $8 \%$ of their baseline weight. Participants completed surveys on their social support, ${ }^{17}$ readiness to lose weight, ${ }^{18}$ and state of health. All participants selected whether to receive study communications by text message, e-mail, or both.

Participants completed weigh-ins at 12, 24, and 36 weeks virtually by using Facetime or Skype to confirm their identity and transmit weight data. All patients received \$20 for completing enrollment, $\$ 20$ for completing the 12-week weigh-in, $\$ 40$ for completing the 24-week weigh-in, and $\$ 40$ for completing the 36-week weigh-in. Participants were allowed to keep the weight scale after the trial concluded. Accumulated earnings were mailed in the form of a bank check to participants at the end of each month.

\section{Participants}

Recruitment occurred from November 11, 2015 to March 11, 2016 using flyers at primary care clinics at the University of Pennsylvania Health System (UPHS) and e-mail invitations to employees at the University of Pennsylvania and UPHS. Participants were eligible if they were age 18 to 70 years old, had a body mass index of 30 or greater, had an iPhone smartphone, and had a family member or friend interested in participating with them. Participants were excluded if participation was infeasible (e.g., inability to provide consent or speak English), unsafe (e.g., history of eating disorder, binging, laxative or diuretic use; metastatic cancer; pregnant or breastfeeding), they were already enrolled in another weight loss study, or they had any reason or medical condition prohibiting them from completing the 36-week trial.

\section{Randomization and Interventions}

Teams were randomly assigned to a study arm using a computerized random number generator with block sizes of three teams. All investigators, statisticians, and data analysts were blinded to arm assignments until the study and analysis were completed.

Participants in teams assigned to control received no other interventions. Participants in the gamification arms were given weekly weight targets over 24 weeks that declined evenly each week from their baseline to their target. For example, a participant with a goal to lose $12 \mathrm{lbs}$ would have been asked to meet weight targets that declined by $0.5 \mathrm{lbs}$ each of the 24 weeks. They were also entered into a game with their teammate for 36 weeks that was designed using insights from behavioral economics to address predictable barriers to behavior change and to enhance social incentives, similar to prior work. ${ }^{11}$ First, participants signed a commitment pledge to try their best to achieve their step goal by 24 weeks and maintain it through 36 weeks. Precommitment has been demonstrated to motivate behavior change. ${ }^{19,20}$ Second, every Monday, the team was endowed with 70 points (10 for each day of the upcoming week) and a weight target for the week. Each day, the team was informed of the one member who was selected at random to represent their team. If that member weighed in on the prior day (regardless of the weight), the team kept its points; otherwise, 10 points were lost. This design leveraged three important psychological principles to increase weight scale utilization: individuals tend to be more motivated by losses than gains, ${ }^{12}$ behavior is often better sustained by variable than constant reinforcement, ${ }^{21}$ and individuals tend to be more motivated for aspirational behavior around temporal landmarks, such as the beginning of the week (the fresh start effect). ${ }^{22}$ Third, if the team had 40 points or more at the end of the week and both individuals met their weight target for the week on at least 1 day, the team advanced up a level (bronze, silver, gold, platinum). If not, the team dropped a level. This design creates achievable goal gradients (the notion that the next highest level was attainable), a sense of social status, 
progression through the game, and longer-term loss aversion for teams that reached higher levels. Teams began in silver and were informed of their new level and weight target each Monday. Teams were not told how other teams were doing. Finally, participants were informed that if they met their weight loss goal, they would receive a trophy as a reward at the end of the study.

After 24 weeks, participants were asked to select whether they would like to strive for either their full remaining goal by 36 weeks or half of it. The gamification intervention was continued through 36 weeks with the updated weight target.

Participants in the gamification with PCP sharing arm also had their data sent to their PCP on a regular basis for 36 weeks. If the participant's PCP was at Penn, the data was sent to the electronic health record using Apple Healthkit's integration with EPIC through our patient portal smartphone application. This data would appear daily in the patient's chart but only be viewed by the PCP when they accessed it. PCPs were sent an EPIC message for each patient for which data was sent electronically. If the participant's PCP was outside of our institution, they were mailed a letter each month that included the lowest weight and average steps for each week in the past month. All participants also received a copy of a letter to the PCP each month by mail. PCPs were encouraged to discuss this information with their patients as they saw fit with the hope that it would provide an additional social incentive to promote weight loss.

\section{Outcome Measures}

The primary outcome was change in weight at 24 weeks. Secondary outcomes included change in weight at 36 weeks, mean step counts during the intervention and follow-up period, and proportion of participant-days achieving step goals during the intervention and follow-up period.

\section{Statistical Analysis}

A priori, we estimated that a sample of 150 participants $(25$ two-person teams per arm) would provide at least $80 \%$ power to detect an 8-lbs difference in weight loss between any of the intervention arms and control, assuming a standard deviation of $10 \mathrm{lbs}$, a $20 \%$ dropout rate, and using a conservative Bonferroni adjustment of the type I error rate with a twosided $\alpha$ level of 0.025 . Due to high interest in the study, we increased the sample size to allow 196 participants to enroll.

All randomly assigned participants were included in the intention-to-treat analysis. Weight data could be missing if a participant declined or did not follow through with a scheduled weigh-in. Step data could be missing for any day if a participant did not use the smartphone to track activity or did not upload data. For each participant on each day of the study (participant-day level), the number of steps achieved was obtained as a continuous variable and this was used to estimate mean daily steps. These data were dichotomized at the participant-day level to create a binary variable indicating whether or not each participant achieved his or her step goal and this variable was used to estimate the proportion of participant-days that step goals were achieved.

For the main analysis, we used multiple imputation (using the MICE package in $R$ ) for missing weight data and for step data that were missing or less than 1000 steps. Evidence indicates that step values less than 1000 may not represent accurate data capture, ${ }^{23,24}$ and we have accounted for these values as missing data in prior work. ${ }^{11,12,14-16}$ Five imputations were conducted using the following predictors of missing data: baseline weight, age, sex, race/ethnicity, education, marital status, household income, self-reported health, stage of change, and social support score. Results were combined using Rubin's standard rules. ${ }^{25}$ Secondary analyses were conducted using collected data without multiple imputation.

Unadjusted analyses estimated the change in weight within arm from baseline to 12,24 , and 36 weeks, as well as the mean step counts for the intervention and follow-up periods.

In adjusted analyses, we fit linear mixed models to the outcome variables, adjusting for baseline weight and clustering at the level of the team. Models using step data were also adjusted for a participant's repeated observations. Analyses were conducted using $R$ (version 3.4.1).

\section{RESULTS}

One hundred ninety-six participants comprising 98 teams were randomized (Fig. 1). The mean age of participants was 41.4 years and $85.7 \%$ were women (Table 1). Baseline measures were similar between arms with an overall mean body mass index of 36.3 and mean weight of $225.9 \mathrm{lbs}$. Participants had a mean weight loss goal of $17.2 \mathrm{lbs}$.

Mean weight loss outcomes by arm are displayed in Table 2. At 24 weeks, participants lost significant weight from baseline in the control arm (mean: $-3.9 \mathrm{lbs} ; 95 \% \mathrm{CI}:-6.1$ to $-1.7 ; P<0.001$ ), the gamification arm (mean: $-6.6 \mathrm{lbs} ; 95 \%$ CI: -9.4 to $-3.9 ; P<0.001)$, and the gamification arm with PCP data sharing (mean: $-4.8 \mathrm{lbs} ; 95 \% \mathrm{CI}-7.4$ to -2.3 ; $P<0.001)$. At 36 weeks, weight loss from baseline remained significant in the control arm (mean: $-3.5 \mathrm{lbs} ; 95 \% \mathrm{CI}:-6.1$ to $-0.8 ; P=0.01$ ), the gamification arm (mean: $-6.3 \mathrm{lbs} ; 95 \%$ CI: -9.2 to $-3.3 ; P<0.001)$, and the gamification arm with PCP data sharing (mean: $-5.2 \mathrm{lbs} ; 95 \% \mathrm{CI}:-8.5$ to -2.0 ; $P<0.01)$. However, in the main adjusted model, there were no significant differences in weight loss between each of the intervention arms and control at either 12, 24, or 36 weeks.

Mean step counts by arm are displayed in Table 3. The gamification arm had the highest mean step count; however, in the main adjusted model, there were no significant differences between each of the intervention arms and control. During the 24-week intervention, the proportion of participant days that the goal of 10,000 steps was achieved was $15.5 \%$ in control, $17.0 \%$ in the gamification arm, and $12.4 \%$ in the gamification 


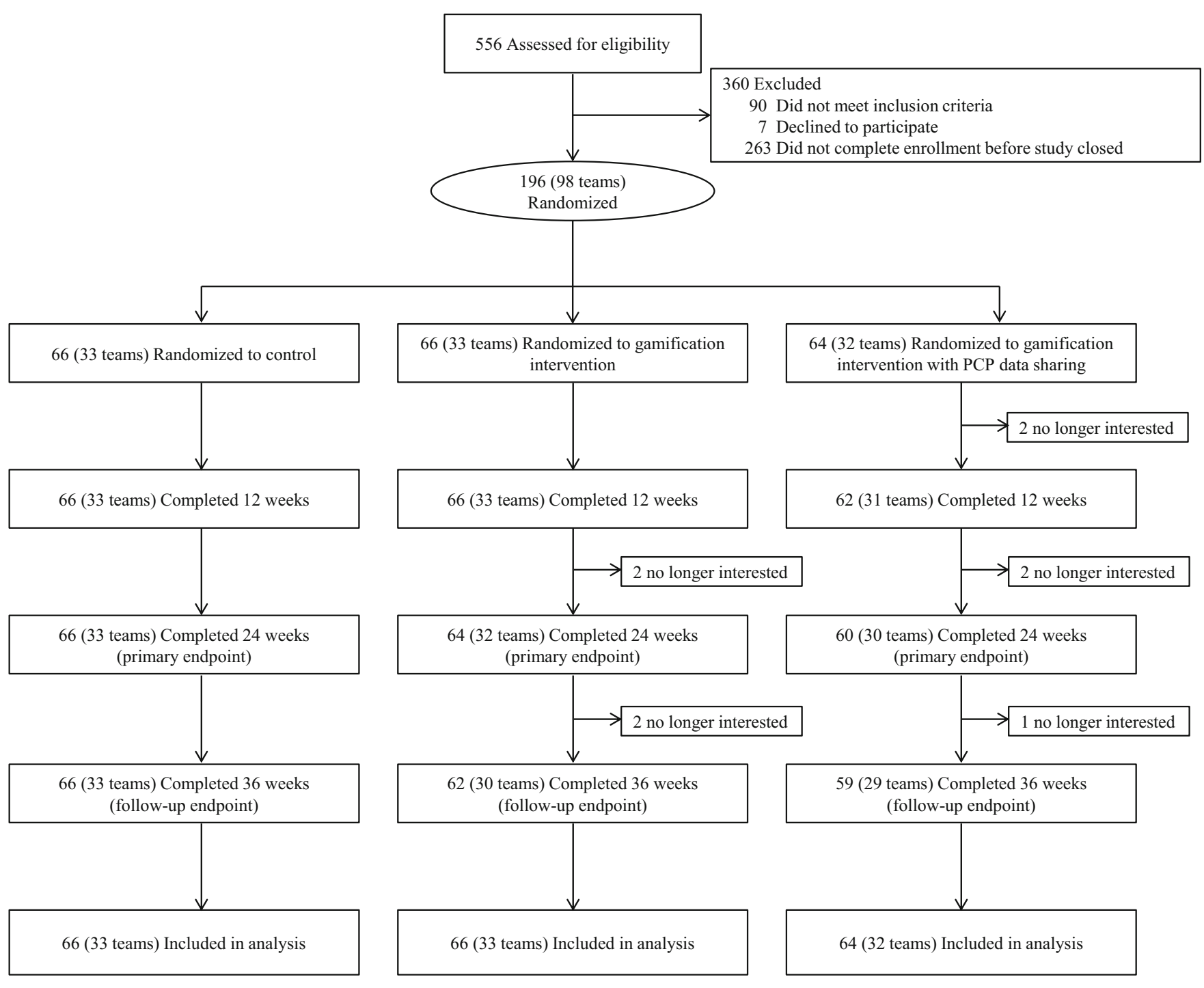

Fig. 1 Study flow diagram. All participants formed teams of two people that knew each other, tracked step counts using their smartphones, and were given a wireless weight scale.

arm with PCP data sharing. These declined to $11.4,12.9$, and $10.3 \%$, respectively, during the follow-up period.

In subgroup analysis by whether or not the teammates lived together, there was greater mean weight loss among participants that lived together compared to those that did not, particularly among the intervention arms at both 24 and 36 weeks (Fig. 2). At 24 weeks, participants in the gamification arm that lived together had a mean weight change of $9.8 \mathrm{lbs}(95 \% \mathrm{CI}:-17.6$ to $-2.0 ; P=0.01$ compared to baseline) compared to participants that did not live together of $6.1 \mathrm{lbs}(95 \% \mathrm{CI}:-9.0$ to $-3.2 ; P<0.001)$. At 36 weeks, participants in this arm that lived together had a mean weight change of $-8.6 \mathrm{lbs}(95 \% \mathrm{CI}:-16.2$ to $-1.1 ; P=0.03)$ compared to participants that did not live together of $-5.8 \mathrm{lbs}$ (95\% CI: -9.1 to $-2.6 ; P<0.001)$.

All results were similar in sensitivity models the used collected data without multiple imputation (Online Appendix 2). There were no adverse events reported during the trial.

\section{DISCUSSION}

In this trial, we found that using digital health devices to track health behaviors with a partner led to significant weight loss through 36 weeks for all three arms. However, the gamification interventions were not effective at promoting weight loss when compared to control.

Our findings reveal several important insights for future intervention design. First, we found that teammates who lived together had greater mean weight loss than teammates who lived separately. This finding was larger among the intervention arms in which a social incentive was used. In previous work, ${ }^{26}$ Christakis and Fowler used a large retrospective cohort to demonstrate that trends in weight gain propagated through social networks. Jackson and colleagues used a different retrospective cohort to demonstrate that when one partner lost weight, the other partner was more likely to also lose weight. $^{27}$ Our study is one of the first to demonstrate this 
Table 1 Characteristics of Study Participants

\begin{tabular}{|c|c|c|c|c|}
\hline Characteristic & Control $(n=66)$ & Gamification $(n=66)$ & $\begin{array}{l}\text { Gamification with PCP } \\
\text { data sharing }(n=64)\end{array}$ & $P$ value \\
\hline \multicolumn{5}{|l|}{ Sociodemographics } \\
\hline Age, mean (SD) & $42.5(12.9)$ & $42.3(11.5)$ & $39.3(10.6)$ & 0.22 \\
\hline Female sex, No. (\%) & $61(92.4)$ & $55(83.3)$ & $52(81.3)$ & 0.15 \\
\hline \multicolumn{5}{|l|}{ Race/ethnicity, No. (\%) } \\
\hline White non-Hispanic & $40(60.6)$ & $38(57.6)$ & $42(65.6)$ & \\
\hline African American non-Hispanic & $20(30.3)$ & $22(33.3)$ & $18(28.1)$ & \\
\hline Other non-Hispanic & $4(6.1)$ & $4(6.1)$ & $3(4.7)$ & \\
\hline Hispanic & $2(3.0)$ & $2(3.0)$ & $1(1.6)$ & \\
\hline \multicolumn{4}{|l|}{ Race/Ethnicity, no. (\%) } & \multirow{4}{*}{0.64} \\
\hline White non-Hispanic & $40(60.6)$ & $38(57.6)$ & $42(65.6)$ & \\
\hline African American non-Hispanic & $20(30.3)$ & $22(33.3)$ & $18(28.1)$ & \\
\hline Other & $6(9.1)$ & $6(9.1)$ & $4(6.3)$ & \\
\hline \multicolumn{5}{|l|}{ Education, no. (\%) } \\
\hline Less than college graduate & $21(31.8)$ & $20(30.3)$ & $18(28.1)$ & \multirow{2}{*}{0.90} \\
\hline College graduate & $45(68.2)$ & $46(69.7)$ & $46(71.9)$ & \\
\hline \multicolumn{5}{|l|}{ Marital status, no. (\%) } \\
\hline Married & $37(56.1)$ & $34(51.5)$ & $42(65.6)$ & \multirow{2}{*}{0.25} \\
\hline Other & $21(31.8)$ & $20(30.3)$ & $18(28.1)$ & \\
\hline \multicolumn{4}{|l|}{ Annual household income, no. (\%) } & \multirow{5}{*}{0.99} \\
\hline Less than $\$ 50,000$ & $13(19.7)$ & $14(21.2)$ & $14(21.9)$ & \\
\hline$\$ 50,000$ to $\$ 100,000$ & $22(33.3)$ & $23(34.8)$ & 19 (29.7) & \\
\hline Greater than $\$ 100,000$ & $23(34.8)$ & $27(40.9)$ & $24(37.5)$ & \\
\hline Unknown & $8(12.1)$ & $2(3.0)$ & $7(10.9)$ & \\
\hline \multicolumn{5}{|l|}{ Baseline measures } \\
\hline Body mass index, mean (SD) & $37.2(5.7)$ & $36.0(5.2)$ & $35.5(5.0)$ & 0.18 \\
\hline Baseline weight, mean (SD) & $228.8(43.6)$ & $224.7(41.5)$ & $224.1(39.3)$ & 0.78 \\
\hline Weight loss goal selection, mean lbs (SD) & $17.4(3.2)$ & $17.3(3.5)$ & $16.9(3.2)$ & 0.68 \\
\hline Lives with teammate, no. $(\%)$ & $16(24.2)$ & $10(15.2)$ & $21(32.8)$ & 0.06 \\
\hline Relationship with teammate, mean years (SD) & $17.8(13.9)$ & $12.1(13.9)$ & $15.5(10.1)$ & 0.03 \\
\hline Social support scale, mean (SD)* & $84.0(11.8)$ & $83.2(16.9)$ & $81.6(16.7)$ & 0.67 \\
\hline \multicolumn{5}{|l|}{ State of health, no. (\%) } \\
\hline Excellent & $2(3.0)$ & $5(7.6)$ & $2(3.1)$ & \multirow[t]{5}{*}{0.38} \\
\hline Very good & $30(45.5)$ & $19(28.8)$ & $29(45.3)$ & \\
\hline Good & $28(42.4)$ & $36(54.5)$ & $27(42.2)$ & \\
\hline Fair & $5(7.6)$ & $6(9.1)$ & $6(9.4)$ & \\
\hline \multirow{2}{*}{\multicolumn{5}{|c|}{ Stage of change, no. $(\%) \dagger$}} \\
\hline & & & & \\
\hline Maintenance ( $>6$ months) & $29(43.9)$ & $29(43.9)$ & $23(35.9)$ & \multirow[t]{5}{*}{0.46} \\
\hline Action (<6 months) & $14(21.2)$ & $10(15.2)$ & $10(15.6)$ & \\
\hline Preparation (next 30 days) & $20(30.3)$ & $18(27.3)$ & $23(35.9)$ & \\
\hline Contemplation (next 6 months) & $3(4.5)$ & $9(13.6)$ & $8(12.5)$ & \\
\hline Precontemplation (not ready) & $0(0)$ & $0(0)$ & $0(0)$ & \\
\hline PCP received data through Epic-HealthKit & $28(42.4)$ & $38(57.6)$ & $31(48.4)$ & 0.22 \\
\hline
\end{tabular}

SD standard deviation, $P C P$ primary care physician

*Scale of 1 to 100 using the Medical Outcomes Study Validated Survey

tProchaska stage of change for trying to lose weight

Table 2 Weight Loss Outcomes

\begin{tabular}{|c|c|c|c|c|c|}
\hline Measure & Control & Gamification & $\begin{array}{l}\text { Gamification } \\
\text { with PCP data } \\
\text { sharing }\end{array}$ & $\begin{array}{l}\text { Adjusted difference } \\
\text { (gamification vs. control) }\end{array}$ & $\begin{array}{l}\text { Adjusted difference } \\
\text { (gamification with } \\
\text { PCP data sharing } \\
\text { vs. control) }\end{array}$ \\
\hline \multicolumn{6}{|l|}{12 weeks } \\
\hline Mean weight change, lbs & -3.3 & -5.9 & -3.5 & -2.7 & -0.4 \\
\hline $95 \% \mathrm{CI}$ & $-4.8,-1.7$ & $-8.1,-3.7$ & $-5.3,-1.7$ & $-5.5,0.1$ & $-3.2,2.5$ \\
\hline$P$ value & $<0.001$ & $<0.001$ & $<0.001$ & 0.06 & 0.81 \\
\hline \multicolumn{6}{|l|}{24 weeks (primary endpoint) } \\
\hline Mean weight change, lbs & -3.9 & -6.6 & -4.8 & -2.9 & -1.1 \\
\hline $95 \% \mathrm{CI}$ & $-6.1,-1.7$ & $-9.4,-3.9$ & $-7.4,-2.3$ & $-6.7,0.9$ & $-5.1,2.9$ \\
\hline$P$ value & $<0.001$ & $<0.001$ & $<0.001$ & 0.14 & 0.59 \\
\hline \multicolumn{6}{|l|}{36 weeks (follow-up endpoint) } \\
\hline Mean weight change, lbs & -3.5 & -6.3 & -5.2 & -2.9 & -1.9 \\
\hline $95 \% \mathrm{CI}$ & $-6.1,-0.8$ & $-9.2,-3.3$ & $-8.5,-2.0$ & $-7.0,1.1$ & $-6.5,2.7$ \\
\hline$P$ value & 0.01 & $<0.001$ & $<0.01$ & 0.15 & 0.40 \\
\hline
\end{tabular}

lbs pounds, CI confidence interval

*Data from the main model that adjusts for baseline weight and used multiple imputation for missing weight data

tP values within study arms (first three columns) represent change in weight compared to baseline in that study arm. P values within the final two columns represent differences between each intervention and control 
Table 3 Physical Activity Outcomes

\begin{tabular}{|c|c|c|c|c|c|}
\hline Timepoint & $\begin{array}{l}\text { Control, } \\
\text { mean (SD) }\end{array}$ & $\begin{array}{l}\text { Gamification, } \\
\text { mean (SD) }\end{array}$ & $\begin{array}{l}\text { Gamification with } \\
\text { PCP Data Sharing, } \\
\text { mean (SD) }\end{array}$ & $\begin{array}{l}\text { Adjusted difference, } \\
\text { steps (95\% CI) } \\
\text { (gamification vs. } \\
\text { control) }\end{array}$ & $\begin{array}{l}\text { Adjusted difference } \\
\text { (gamification with } \\
\text { PCP data sharing } \\
\text { vs. control) }\end{array}$ \\
\hline $\begin{array}{l}0 \text { to } 24 \text { weeks (primary endpoint) } \\
P \text { value }\end{array}$ & $\begin{array}{l}5711(1949) \\
-\end{array}$ & $6182(2295)$ & $\begin{array}{l}5681(2081) \\
-\end{array}$ & $\begin{array}{l}455(-309,1218) \\
0.24\end{array}$ & $\begin{array}{l}-44(-818,730) \\
0.91\end{array}$ \\
\hline 25 to 36 weeks (follow-up endpoint) & $5112(1678)$ & $5682(2325)$ & $5340(1708)$ & $556(-197,1309)$ & $216(-648,1081)$ \\
\hline$P$ value & - & - & - & 0.15 & 0.62 \\
\hline
\end{tabular}

SD standard deviation, CI confidence interval

*Data from the main model that adjusts for baseline weight and used multiple imputation for miss step data and daily step values less than 1000

relationship between weight loss and social ties in a prospective trial and indicates that future social incentive-based interventions may be more effective if partners live together or have stronger social ties.

Second, sharing data with PCPs did not significantly improve weight loss among participants in the gamification intervention. This could be because we did not actively engage physicians in the trial, and therefore, they may not have been reviewing the data. Or, physicians may not have found the information actionable. Since participants also received a copy of the letter, they may have generated expectations about PCP involvement that were not met, and this could have been demotivating. Future interventions could test ways to better engage clinicians with patients to understand how this type of information could be delivered in a more useful manner. ${ }^{28}$ It may also be the case that physicians do not need to be involved in receiving these data and they could simply facilitate initial engagement with the program which can then be automated to promote behavior change. $^{29}$

Third, this trial leveraged technology in several novel ways that could be used in future trials to increase broad scalability. More than two thirds of adults have a smartphone, ${ }^{30}$ and our previous research has found these devices to be accurate for tracking step counts. ${ }^{16}$ We used video conferencing through

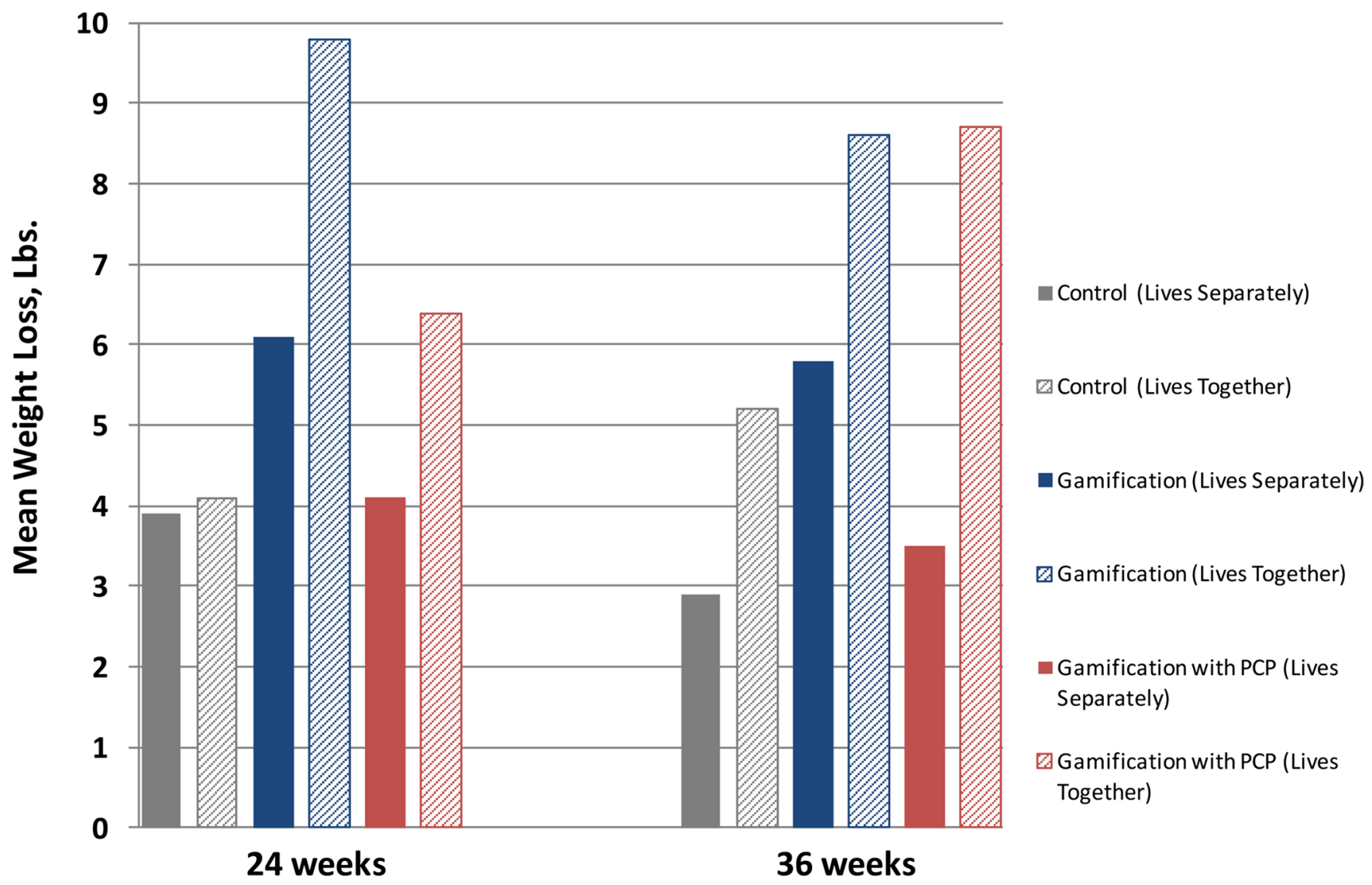

Fig. 2 Weight loss by arm based on if teammates lived together or not. Solid bars represent participants that formed teams but lived separately. Dashed bars represent participants that lived together in the same residence. 
Apple FaceTime or Skype to conduct virtual weigh-ins with participants, which saved them the time and cost of traveling for an in-person weigh-in. The gamification interventions were automated through a technology platform and required minimal personnel for oversight. ${ }^{31}$ Future studies could test ways to use these approaches in different populations.

Our study is subject to several limitations. First, participants were mostly women, and had to have an iPhone, which may limit generalizability. Second, we did not obtain data on baseline physical activity and step counts were only captured, while participants were carrying their smartphones. Third, our control group was different from usual care in that two teammates participated together and used digital health devices. Finally, we did not test the gamification intervention in teams of individuals that did not know each other.

\section{CONCLUSIONS}

The use of digital health devices to track health behaviors with a partner led to significant weight loss through 36 weeks, particularly among teammates that lived together. However, the gamification interventions were not effective at promoting weight loss when compared to control. Future studies could test different ways to design the gamification interventions to better leverage strong social connections and to better engage clinicians.

Corresponding Author: Mitesh S. Patel, MD, MBA, MS; Crescenz Veterans Affairs Medical Center, Philadelphia, PA, USA (e-mail: mpatel@pennmedicine.upenn.edu).

Funding Support This study was funded by the grants from the University of Pennsylvania Center for Therapeutic Effectiveness Research (CTER) and the McCabe Fund. The funding sources had no role in the design and conduct of the study; collection, management, analysis, and interpretation of the data; preparation, review, or approval of the manuscript; and decision to submit the manuscript for publication.

\section{Compliance with Ethical Standards:}

Conflict of Interest: Dr. Patel is supported by career development awards from the Department of Veterans Affairs HSR\&D and the Doris Duke Charitable Foundation. Dr. Patel is also a principal at Catalyst Health, a technology and behavior change consulting firm. Dr. Patel also has received research funding from Deloitte, which is not related to the work described in this manuscript. All remaining authors declare that they do not have a conflict of interest.

\section{REFERENCES}

1. Flegal KM, Kruszon-Moran D, Carroll MD, Fryar CD, Ogden CL. Trends in Obesity Among Adults in the United States, 2005 to 2014 JAMA 2016;315(21):2284-2291.

2. Collaborators GBDO, Afshin A, Forouzanfar MH, et al. Health Effects of Overweight and Obesity in 195 Countries over 25 Years. N Engl J Med 2017;377(1):13-27.

3. Snook KR, Hansen AR, Duke CH, Finch KC, Hackney AA, Zhang J. Change in Percentages of Adults With Overweight or Obesity Trying to Lose Weight, 1988-2014. JAMA 2017;317(9):971-973.
4. Jensen MD, Ryan DH, Apovian CM, et al. 2013 AHA/ACC/TOS guideline for the management of overweight and obesity in adults: a report of the American College of Cardiology/American Heart Association Task Force on Practice Guidelines and The Obesity Society. Circulation 2014;129(25 Suppl 2):S102-138.

5. Kushner RF, Ryan DH. Assessment and lifestyle management of patients with obesity: clinical recommendations from systematic reviews. JAMA 2014;312(9):943-952.

6. Soleymani T, Daniel S, Garvey WT. Weight maintenance: challenges, tools and strategies for primary care physicians. Obes Rev 2016;17(1):8193.

7. Edwards EA, Lumsden J, Rivas C, et al. Gamification for health promotion: systematic review of behaviour change techniques in smartphone apps. BMJ Open 2016;6(10):e012447.

8. Kawachi I. It's All in the Game-The Uses of Gamification to Motivate Behavior Change. JAMA Intern Med 2017;177(11):1593-1594.

9. Miller AS, Cafazzo JA, Seto E. A game plan: Gamification design principles in mHealth applications for chronic disease management. Health Informatics J 2016;22(2):184-193.

10. Patel MS, Foschini L, Kurtzman GW, et al. Using wearable devices and smartphones to track physical activity: Initial activation, sustained use, and step counts across sociodemographic characteristics in a national sample. Ann Intern Med 2017; Published Online, Sept 26.

11. Patel MS, Benjamin EJ, Volpp KG, et al. Effect of a Game-Based Intervention Designed to Enhance Social Incentives to Increase Physical Activity Among Families: The BE FIT Randomized Clinical Trial. JAMA Intern Med 2017;177(11):1586-1593.

12. Patel MS, Asch DA, Rosin R, et al. Framing Financial Incentives to Increase Physical Activity Among Overweight and Obese Adults: A Randomized, Controlled Trial. Ann Intern Med 2016;164(6):385-394.

13. Patel MS, Asch DA, Troxel AB, et al. Premium-Based Financial Incentives Did Not Promote Workplace Weight Loss In A 2013-15 Study. Health Aff (Millwood) 2016;35(1):71-79.

14. Patel MS, Asch DA, Rosin R, et al. Individual Versus Team-Based Financial Incentives to Increase Physical Activity: A Randomized, Controlled Trial. J Gen Intern Med 2016;31(7):746-754.

15. Patel MS, Volpp KG, Rosin R, et al. A Randomized Trial of Social Comparison Feedback and Financial Incentives to Increase Physical Activity. Am J Health Promot 2016;30(6):416-424.

16. Case MA, Burwick HA, Volpp KG, Patel MS. Accuracy of smartphone applications and wearable devices for tracking physical activity data JAMA 2015;313(6):625-626.

17. Sherbourne CD, Stewart AL. The MOS social support survey. Soc Sci Med 1991;32(6):705-714.

18. Prochaska Jo, Velicer WF. The transtheoretical model of health behavior change. Am J Health Promot 1997; 12(1):38-48.

19. Ariely D, Wertenbroch K. Procrastination, deadlines, and performance: self-control by precommitment. Psychol Sci. 2002;13(3):219-224.

20. Rogers T, Milkman KL, Volpp KG. Commitment devices: using initiatives to change behavior. JAMA. 2014;311(20):2065-2066.

21. Skinner BF. The behavior of organisms: an experimental analysis. New York, London,: D. Appleton-Century Company; 1938.

22. Dai H, Milkman KL, Riis J. The Fresh Start Effect: Temporal Landmarks Motivate Aspirational Behavior. Manag Sci 2014;60(10):2563-2582.

23. Bassett DR Jr., Wyatt HR, Thompson H, Peters JC, Hill JO Pedometer-measured physical activity and health behaviors in U.S. adults. Med Sci Sports Exerc 2010;42(10):1819-1825.

24. Kang M, Rowe DA, Barreira TV, Robinson TS, Mahar MT. Individual information-centered approach for handling physical activity missing data. Res Q Exerc Sport 2009;80(2):131-137.

25. Rubin DB. Multiple imputation for nonresponse in surveys. New York, NY: Wiley; 1987.

26. Christakis NA, Fowler JH. The spread of obesity in a large social network over 32 years. N Engl J Med 2007;357(4):370-379.

27. Jackson SE, Steptoe A, Wardle J. The influence of partner's behavior on health behavior change: the English Longitudinal Study of Ageing. JAMA Intern Med 2015; 175(3):385-392.

28. Roess A. The Promise, Growth, and Reality of Mobile Health-Another Data-free Zone. N Engl J Med 2017;377(21):2010-2011.

29. Asch DA, Muller RW, Volpp KG. Automated hovering in health carewatching over the 5000 hours. N Engl J Med 2012;367(1):1-3.

30. The US digital consumer report. 2014; http://www.nielsen.com/us/en/ insights/reports/2014/the-us-digital-consumer-report.html.

31. Asch DA, Volpp KG. On the Way to Health. LDI Issue Brief 2012;17(9):1- 